\title{
Physicochemical properties of dragon fruit peel pectin and citrus peel pectin: a comparison
}

\author{
${ }^{1}$ Muhammad, N.W.F., ${ }^{1, *}$ Nurrulhidayah A.F., ${ }^{1}$ Hamzah., M.S., ${ }^{1}$ Rashidi, O. and \\ ${ }^{2}$ Rohman, A. \\ ${ }^{1}$ International Institute for Halal Research and Training (INHART), International Islamic University \\ Malaysia, Gombak, Selangor \\ ${ }^{2}$ Department of Pharmaceutical Chemistry Faculty of Pharmacy Universitas Gadjah Mada Yogyakarta \\ 55281 Indonesia
}

\section{Article history: \\ Received: 19 August 2019 Received in revised form: 21 January 2020 \\ Accepted: 26 February 2020 Available Online: 10 March 2020}

\section{Keywords:}

Pectin extraction,

Dragon fruit peel,

Characterization,

Commercial pectin

\section{DOI:}

https://doi.org/10.26656/fr.2017.4(S1).S14

\begin{abstract}
Dragon fruit is a tropical fruit belongs to Cactae family of genus Hylocereus. Popular as buah naga in Malay, dragon fruit is not only sought after for its wonderful taste, but this fruit is also nutritionally and medicinally attractive for consumers. The dragon fruit flesh is usually eaten raw or it is processed into juices and the remaining peel will be discarded. To minimize the waste created from dragon fruit consumption, an idea of transforming the peel of dragon fruit into edible pectin has been proposed. Pectin can be found in food products as a gelling agent and it is used to maintain the quality of foods. Recent market demand for pectin is increasing annually and to meet the supply-demand, researchers are working towards obtaining pectin from available non-conventional sources. In this study, pectin was extracted from dragon fruit peel by hot acid extraction at $\mathrm{pH} 3.5$ and 75 mins of extraction. Distilled water was used as a solvent and the acidic environment was achieved with dilute $\mathrm{HCl}$. Degree of esterification (DE) analysis was performed by FTIR. The extracted pectin was categorized as high methoxyl pectin based on DE (52\%). The endothermic properties of dragon fruit pectin analyzed by DSC indicating the stability of extracted pectin compared to citrus peel pectin. Pectin extracted was characterized in terms of moisture $(14.03 \pm 1.925)$, ash content $(8.73 \pm 1.218)$, as well as water and oilholding capacity $(4.08 \pm 0.0 .81)(2.18 \pm 0.096)$, swelling capacity $(5.94 \pm 1.271)$ and texture profile in terms of gumminess $(33.66 \pm 6.05)$, cohesiveness $(1.06 \pm 0.08)$ and hardness $(31.63 \pm 3.81)$. All characteristics were compared with citrus peel pectin.
\end{abstract}

\section{Introduction}

Red dragon fruit (Hylocereus polyrhizus) is an exotic, sweet and nutritionally wise fruit that is widely cultivated around Southeast Asia. In Malaysia, the annual production of dragon fruit is about 10, 961 tons (Hoe, 2017). Red dragon fruit is highly sought after because of their high nutritional content. Dragon fruit contains up to $9 \mathrm{~g}$ per $100 \mathrm{~g}$ of vitamin $\mathrm{C}$ which is the highest in the fruit among other vitamins (Perween et al., 2018). Protein, carbohydrate, fat, B1, B2, and B3 vitamins, thiamine, niacin, flavonoids, betacyanin are among any other nutrients that can be found in dragon fruit (Hashim, 2018). The dragon fruit is eaten as fresh fruit, peeling the skin away. They are also refined into juice, beverages and syrups. The peel, considered waste from the processing of dragon fruit, is about $22 \%$ of the whole fruit . Such waste is also abundant, according to literatures, with beneficial compounds like flavonoids and pectin (Hashim, 2018) (Ismail et al., 2012; Muhammad et al., 2014). Dragon fruit peel consists mainly of pectin (10.79\%), betacyanin pigments (150.46/ $100 \mathrm{~g} \mathrm{db}$ ) and a total dietary fibre of up to $69.3 \%$ (Chia and Chong, 2015). Commercial pectin has been most prevalently derived from apple pomace and citrus peel and the use of dragon fruit waste to produce value-added ingredients such as pectin has a huge potential.

The word 'pectin' came from Latin and was first developed by Henri Braconnot in 1825. Pectin is a standardized heteropolysaccharide composed of $\alpha-1,4$ bound D- galacturonic acid which is commonly found in the primary cell walls of terrestrial plants. The use of pectin as a gelling agent was developed in the food industry as early as in the last two centuries. (Sriamornsak, 2003). Pectin has been used in food 
products such as jellies, jams, confectionery products, frozen foods, baking products and drinks as a gelling agent, thickener, emulsion and stabiliser. Pectin demand is increasing from time to time and pectin from various sources have been investigated to cater the growing needs such as banana, mango, pumpkin, blueberry, sugar beet, grapefruit, and watermelon (Khan et al., 2014; Castillo-Israel et al., 2015; Girma and Worku, 2016; Huang et al., 2017; Petkowicz et al., 2017 Koh et al., 2018; Dona, 2019). The structure and characteristics of pectin can vary depending on its source and recovery techniques. Pectin attribute has influenced how it is used in the industry and the degree of esterification (DE) is an important feature in exploring the efficacy of pectin gelling agent (Zaid et al., 2019).

Earlier studies have reported findings of pectin from the peel of dragon fruit and citrus. Pectins are complex carbohydrate molecules that are used in numerous food applications as a gelling agent, thickener, stabiliser, and emulsifier. Dragon fruit (Hylocereus polyrhizus) is one of the tropical fruits that belong to the cactus family, Cactaceae. Since the peels of dragon fruit are often discarded as waste, it would be an advantage to convert it into a value-added product such as pectin. The objective of this study was to investigate the extraction of pectin from dragon fruit peels under different extraction time using hot water extraction method. The dragon fruit peels were extracted using distilled water at $80^{\circ} \mathrm{C}$ with different extraction time of $20,40,60$ and 80 mins. The extracted pectin was characterised by its yield, moisture and ash content, degree of esterification and antioxidant activity. Determination of moisture and ash content was conducted using AOAC standard method. The determination of the degree of esterification of pectin was performed using Fourier Transform Infrared Spectroscopy (FTIR). DPPH assay was used to determine the antioxidant activity of the pectin extract. Based on the result, the yield of pectin decreases (20.34 to $16.20 \%$ ) with the increase of extraction time, moisture contents were between 4 to $6 \%$ while ash contents were between 7 to $10 \%$. Pectin from dragon fruit peels was determined as low methoxyl pectin and has a high percentage of antioxidant activity with a low value of inhibition concentration (IC50) $(0.0063$ to $0.0080 \mathrm{mg} /$ $\mathrm{mL}) .60$ mins extraction sample exhibits the highest antioxidant activity $(81.91 \%$ at $40 \mu \mathrm{g} / \mathrm{mL})$, followed by 80 mins extraction $(81.68 \%$ at $40 \mu \mathrm{g} / \mathrm{mL}), 40 \mathrm{mins}$ extraction $(81.38 \%$ at $40 \mu \mathrm{g} / \mathrm{mL})$ and 20 min extraction $(81.31 \%$ at $40 \mu \mathrm{g} / \mathrm{mL}$ ) (Izalin et al., 2016; Rubaiyi et al., 2016; Abang Zaidel et al., 2017; Ahmed and Sikder, 2019). These fruits may vary in functionality and nutritional properties, depending on their variety. This study builds on the existing knowledge fruit pomaces' nutritional properties. This stresses the need to consider both the nutritional and functional characteristics of a fruit product before being integrated into a food product.

\section{Materials and methods}

\subsection{Sample preparation}

Dragon fruits were obtained from Malaysian Agricultural Research and Development Institute (MARDI)'s supplier. The fruits were washed and the peel were cut into smaller sizes $\left(\approx 2 \mathrm{~cm}^{2}\right)$ and stored in a sealed polyethylene bag in a freezer for $48 \mathrm{hrs}$. The samples were then freeze- dried for $72 \mathrm{hrs}$ using a freeze dryer (Martin Crist, Germany; Alpha 1-4 LD Plus with RZ 2.5 vacuum pump) and ground into fine powder and kept at $4{ }^{\circ} \mathrm{C}$ prior to analysis. Citrus peel pectin was obtained from KES Saintifik (Malaysia) and all reagents were from Sigma-Aldrich (USA).

\subsection{Pectin Extraction}

A total of $8.0 \mathrm{~g}$ of powdered sample was rehydrated with $250 \mathrm{~mL}$ of distilled water. The $\mathrm{pH}$ was adjusted to 3.5 using $1 \mathrm{M}$ hydrochloric acid with the aid of a $\mathrm{pH}$ meter equipped with a temperature compensation probe (METTLER TOLEDO). The extraction process was carried out at $70^{\circ} \mathrm{C}$ using stirring hot- plate (500rpm) for 75 mins. The mixture was then centrifuged for 5 mins at $1000 \mathrm{rpm}$. Thereafter, a double volume of $95 \%$ ethanol was mixed to aid the overnight precipitation. The next day, pectin was isolated using a double layer of cheesecloth and washed three times with $70 \%$ alcohol. The final washing of extracted pectin was done using undiluted alcohol to remove the remaining impurities such as monosaccharide and disaccharide (Tang et al., 2011). Finally, pectin collected was freeze-dried to remove all water for $72 \mathrm{hrs}$. For further examination, the samples were cooled, weighed, ground and stored in small plastic bags. The yield of pectin was calculated as the ratio of the weight of dried pectin to the dried extraction process powder.

\subsection{Degree of Esterification (DE) of pectin (FTIR analysis)}

FTIR analysis was carried out using infrared spectrophotometer $\quad\left(\right.$ Nicolet $^{\mathrm{TM}} \quad$ iS $^{\mathrm{TM}} \quad 10 \quad$ FTIR Spectrometer- Thermo Fisher Scientific). The spectra were recorded in the absorbance range from 4000 to 400 $\mathrm{cm}^{-1}$. Peak area relation of the non- esterified carboxyl groups (COO-) $\left(1614.98 \mathrm{~cm}^{-1}\right)$ and esterified carboxyl groups $(\mathrm{C}=\mathrm{O})\left(1737.77 \mathrm{~cm}^{-1}\right)$ were used to determine the DE. DE was calculated by referring to this calculation:

$$
\mathrm{DE}=\frac{\mathrm{APECG}}{\mathrm{APECG}+\mathrm{APNECG}} \times 100
$$

Where APECG is the peak area of esterified carboxyl 
groups, and APNECG is the peak area of non-esterified carboxyl groups.

\subsection{DSC analysis of extracted pectin}

Differential scanning calorimetry (DSC) was used to measure the change in heat flow by a sample after heating quantitative and qualitatively during the endothermic process. DSC was conducted based on the method described by Wang et al. (2014). Samples (5 g) were heated in a closed aluminum pan at $10^{\circ} \mathrm{C} / \mathrm{min}$ from $-30^{\circ} \mathrm{C}$ to $255^{\circ} \mathrm{C}$. The system was purged with nitrogen gas at a flow rate of $50 \mathrm{~mL} / \mathrm{min}$.

\subsection{Moisture and ash content of extracted pectin}

Moisture and ash content analyses of extracted pectin were performed according to the Association of Official Agricultural Chemists AOAC methods as explained by Jauhari et al. (2013). Moisture content was obtained by drying the sample in the oven at $105^{\circ} \mathrm{C}$ for 4 hrs. For ash content, the sample was burnt in furnace muffle at $550^{\circ} \mathrm{C}$ for $2 \mathrm{hrs}$. All contents were determined in percentage form and calculated based on the followings:

$$
\begin{gathered}
\text { Moisture content }=\frac{\text { weight of residue }}{\text { weight of sample }} \times 100 \\
\text { Ash content }=\frac{\text { weight of ash }}{\text { weight of pectin }} \times 100
\end{gathered}
$$

2.6 Water holding capacity (WHC), oil holding capacity (OHC) and swelling capacity (SC) of extracted pectin

WHC, OHC and SC of extracted pectin were measured using the method by Izalin et al. (2016).

$100 \mathrm{mg}$ of sample was weighed and added into 50 $\mathrm{mL}$ centrifuge tube containing $25 \mathrm{~mL}$ of distilled water. The mixture was incubated overnight at $4^{\circ} \mathrm{C}$, centrifuged for 20 mins at $13^{\circ} \mathrm{C}(600 \times \mathrm{g})$ and left at room temperature for 2 hrs. The dried sample was then weighed to obtain the weight of dry residue. WHC calculation is as below:

$$
\text { WHC }=\frac{\text { Weight of water }(\mathrm{g})}{\text { weight of pectin powder }}
$$

A total of $100 \mathrm{mg}$ of sample was added into a centrifuge tube containing $10 \mathrm{~mL}$ of corn oil to determine the oil-holding capacity $(\mathrm{OHC})$. The content was stirred and centrifuged at $1500 \times \mathrm{g}$ for 30 mins. The supernatant was weighed and $\mathrm{OHC}$ was expressed as below:

$$
\mathrm{OHC}=\frac{\text { weight of supernatant }(\mathrm{g})}{\text { weight of pectin powder }(\mathrm{g})}
$$

For swelling capacity, sample (100 mg) was weighed in a cone-shaped plastic tube. Distilled water $(5 \mathrm{~mL})$ was added into the tube and the mixture was left overnight.
The swelling capacity of the extracted sample was determined using the following equation:

$$
\mathrm{SC}=\frac{\text { volume of swollen material }}{\text { weight of pectin powder }} \times 100
$$

\subsection{Texture profile analysis of extracted pectin}

\subsubsection{Gel preparation}

Pectin gel was prepared according to Rascón-Chu et al. (2009) by adding 3\% pectin concentration and sucrose in aqueous solution. The environmental $\mathrm{pH}$ was adjusted to 2.7 with a few drops of $1 \mathrm{M}$ hydrochloric acid $(\mathrm{HCl})$ and the solution was boiled for 30 mins. Gel formed was kept overnight at $4^{\circ} \mathrm{C}$. The gel was measured using TA- XT Express Texture Analyzer (Stable Micro Systems, England) using 0.5" cylinder probe $(\mathrm{P} / 0.5)$ at $1.0 \mathrm{~mm} / \mathrm{s}$ up to $15 \mathrm{~mm}$ depth. The gel was analyzed for hardness, gumminess and cohesiveness.

\subsection{Statistical analysis}

All collected data were expressed as mean \pm standard deviation (SD). Independent t-test was conducted using XLSTAT-Pro (2014) Statistical Software (Addinsoft, France) at 95\% confidence level is $\mathrm{p}<0.05$.

\section{Results and discussion}

\subsection{Degree of Esterification (DE) of extracted pectin}

FTIR spectroscopy was used to determine the DE of extracted pectin. FTIR includes both direct and nondestructive processes and the procedure requires only a small sample quantity to be completed within a shorter time frame. The DE was estimated at $52 \%$, indicating that the pectin of dragon fruit peel is high methoxyl pectin (HM pectin) (Marić et al., 2018). The previous study reported that the ability to form gel is increasing in HM pectin (Coelho et al., 2017). High methoxyl (HM) pectin is a pectin group with $\mathrm{DE}$ value more than $50 \%$ and low methoxyl (LM) pectin has a DE value of less than 50\% (Mamet et al., 2017). The present finding seems to be consistent but slightly lower than reports of dragon fruit peel pectin DE range of 57 - 63\% (Tang et al., 2011; Adzahan et al., 2014; Tongkham et al., 2017). Possible causes for variation in DE values are the differences in growing environments, plant varieties and pectin extracting conditions (Tongkham et al., 2017).

In the region between $4000-400 \mathrm{~cm}^{-1}$, the FTIR spectra identified the major chemical groups in pectin such as $\mathrm{OH}, \mathrm{COOH}$, and $\mathrm{COOCH}_{3}$ and provided structural information on pectin molecule. Figure 1 display the structural information of pectin. The FTIR spectra of extracted pectin from the peel of dragon fruit are presented in Figure 2(a) and are compared with the spectra for citrus peel pectin Figure 2(b). It could be seen 
that the peak at $3296.92 \mathrm{~cm}^{-1}$ indicates $\mathrm{OH}$ groups and the stretching band around $3400-3200 \mathrm{~cm}^{-1}$ is due to inter - and intra-molecular hydrogen bonds of the galacturonic acid polymer (Coelho et al., 2017; Hashim, 2018). The absorption bound at $2935.67 \mathrm{~cm}^{-1}$ was due to C-H stretching of $\mathrm{CH}_{2}$ groups. The major functional group in pectin is located at the region in between 2000 and 1000 $\mathrm{cm}^{-1}$ of the FTIR spectra. Absorption bands appeared at peak $1737 \mathrm{~cm}^{-1}$ was due to stretching vibrations of nonionized $\mathrm{C}=\mathrm{O}$ groups and the appearance of peak 1614.98 $\mathrm{cm}^{-1}$ is the stretching vibration of carboxyl ions (COO-). These data indicate that the extracted substance is pectin since the spectral region between 1800 and 1500 relates to carboxylic acids and carboxylic esters, which are the key functional groups responsible for the characteristics of pectin resembles the spectral region of citrus peel pectin (Coelho et al., 2017). Also, the fingerprint region for carbohydrate, which is located at wavenumber 800 $1300 \mathrm{~cm}^{-1}$ can be used to identify the major chemical group of polysaccharide (Abang Zaidel et al., 2017).

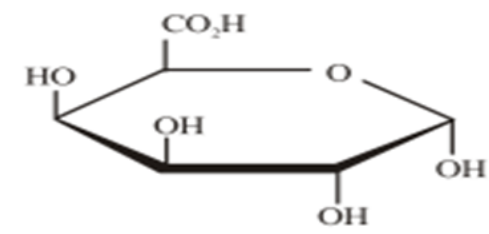

Figure 1. Structure of pectin (Khan et al., 2015)

\subsection{DSC Analysis of dragon fruit peel pectin}

DSC analysis was used to measure the enthalpy changes in the sample as a result of physical and chemical changes by a function of temperature and time. The temperature difference between $-30^{\circ} \mathrm{C}$ and $255^{\circ} \mathrm{C}$ was used to study the thermodynamic properties of dragon fruit peel pectin. Figure $3 \mathrm{a}$ shows a single endothermic peak of dragon fruit peel pectin and Figure
$3 \mathrm{~b}$ shows a distinct endothermic peak of citrus peel pectin in DSC thermogram for comparison. The single endothermic peak at $120^{\circ} \mathrm{C}$ for dragon fruit peel pectin and at $150^{\circ} \mathrm{C}$ for citrus peel pectin was observed in DSC curves. Melting temperature $\left(T_{m}\right)$ was determined from the maximum of the endothermic peak (Mhd Sarbon et al., 2013). $T_{m}\left(122.01^{\circ} \mathrm{C}\right)$ and melting enthalpy $\Delta H_{m}$ $(385.40 \mathrm{~mJ})$ of extracted pectin were higher than those in citrus peel pectin $\left(107.11^{\circ} \mathrm{C}\right.$ and $77.81 \mathrm{~mJ}$, respectively). The values indicated that extracted pectin had a better capacity to sustain water as it requires more energy to remove water completely as reflected by higher melting temperature and enthalpy (Wang et al., 2014). Higher water content and different conformation of dragon fruit peel pectin also shifted the peak of endothermic toward lower temperature (Wang et al., 2016).

\subsection{Moisture and ash content of extracted pectin}

Table 1 shows mean and standard deviation (SD) of moisture and ash content in percentage. Prior studies have reported the importance of moisture and ash content to determine the quality and purity of the pectin (Castillo -Israel et al., 2015). The low moisture content of pectin $(<10 \%)$ is necessary for storage and prevention of bacterial growth that can affect its quality (Girma and Worku, 2016). The moisture content of dragon fruit peel pectin is $14.03 \%$ which is significantly higher than that of citrus peel pectin. The literature stated lower moisture content of dragon fruit peel pectin (4.37-13.13\%) (Ismail et al., 2012; Nurul and Asmah, 2014; Abang Zaidel et al., 2017). A possible explanation for this might be the soggy environment used to keep the sample or human error while conducting the test. Hence, the data could be improved in terms of repeating the experiments and monitoring the sample storage. Several studies using different sources of pectin also resulted in a different amount of moisture content (Castillo-Israel et al., 2015;

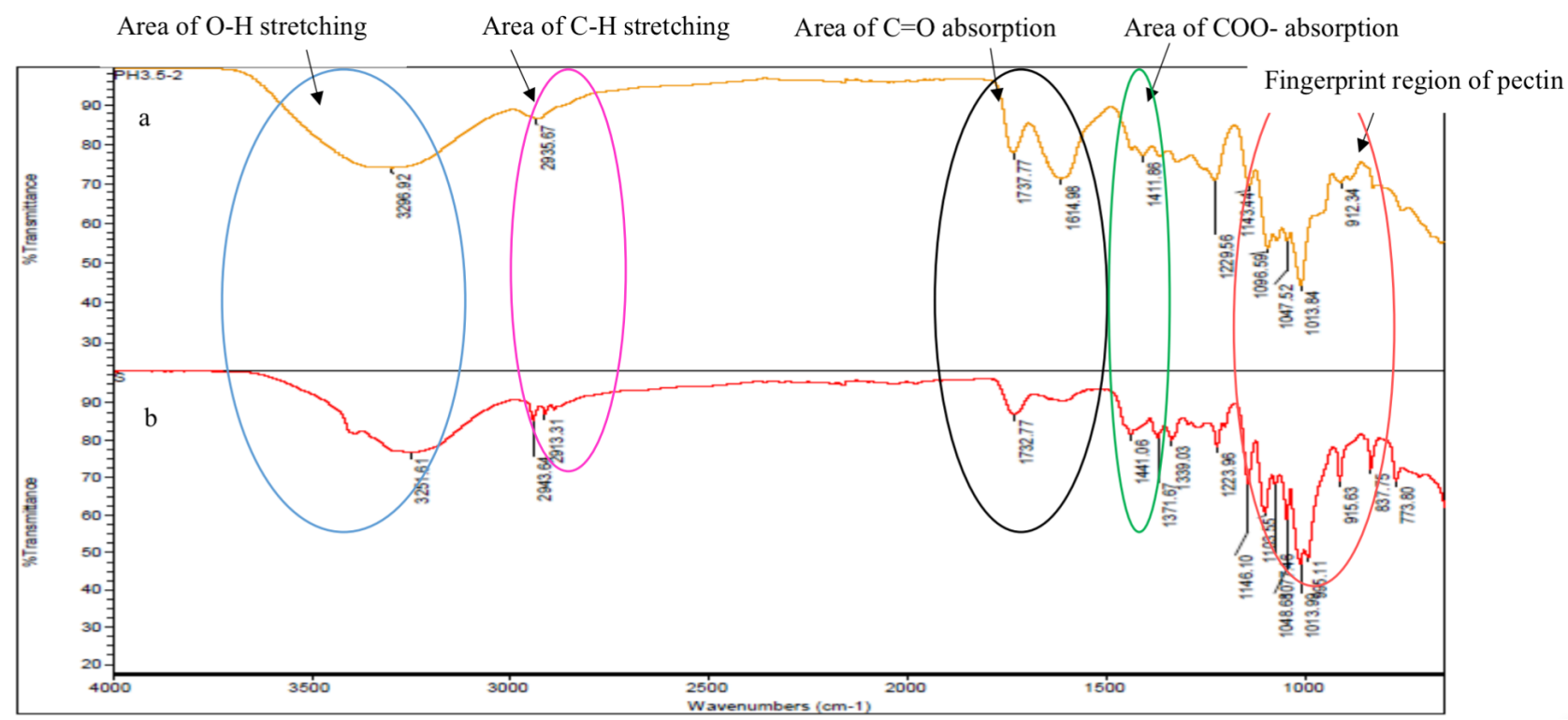

Figure 2. Infrared spectra of functional group for dragon fruit peel pectin (a) and commercial pectin (b). 

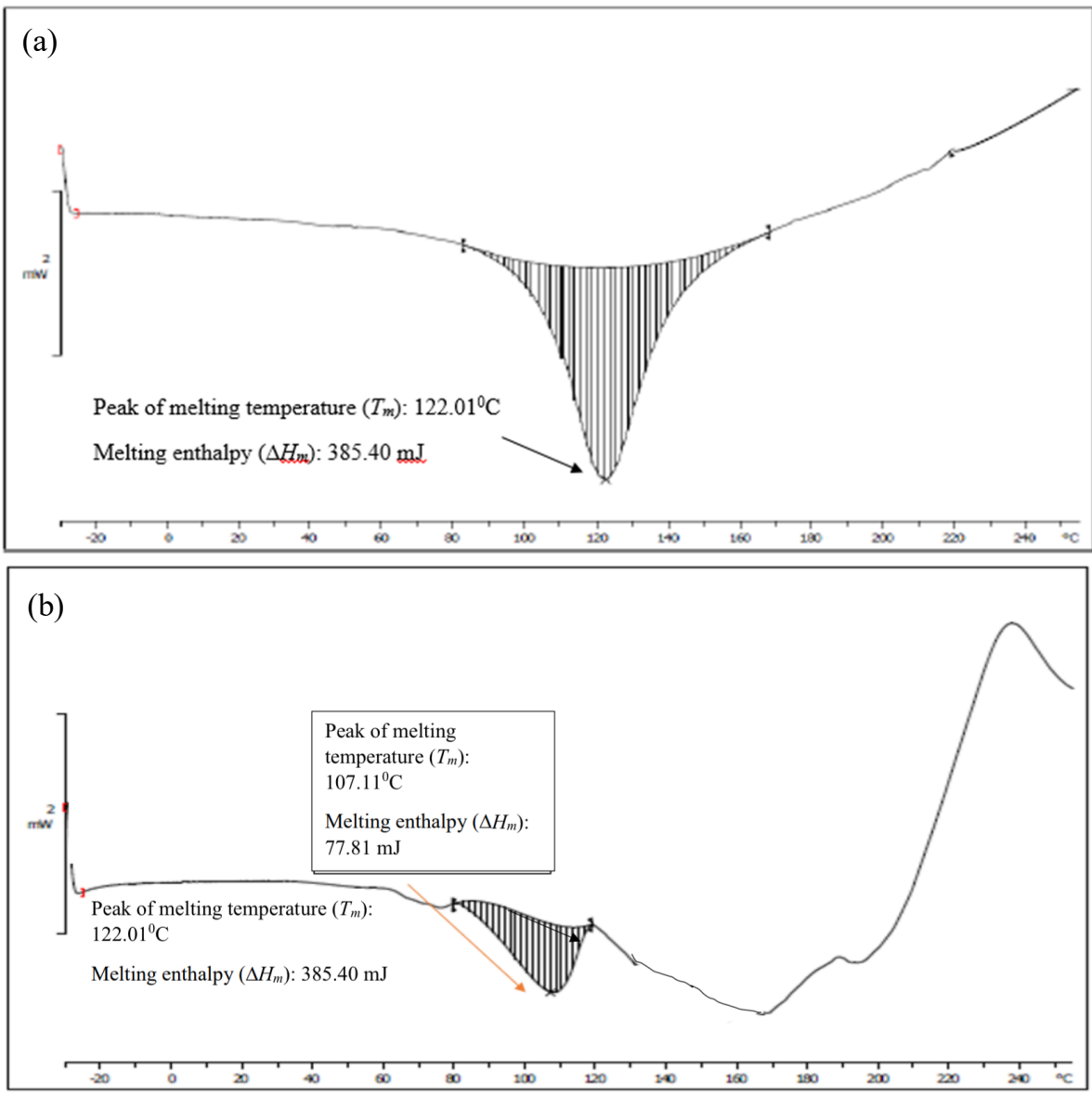

Figure 3. DSC thermograms of (a) dragon fruit peel pectin and (b) citrus peel pectin

Girma and Worku, 2016; Jaswir et al., 2016; Mohamed, 2016). Another possible explanation for this difference is due to the difference in the hygroscopic nature of pectin as different pectin has different degrees of esterification (DE) (Sharma et al., 2014). The moisture content of pectin should be below $10 \%$. Higher reading will cause the humid environment and suitable for bacterial growth (Mohamadzadeh et al., 2010; Ismail et al., 2012; Mohamed, 2016) and reducing the shelf life of the food products (Jauhari et al., 2013).

Table 1. Comparison amount of moisture and ash content in two samples

\begin{tabular}{ccc}
\hline Samples & Moisture (\%) & Ash (\%) \\
\hline Dragon fruit peel pectin & $14.03 \pm 1.925^{\mathrm{a}}$ & $8.73 \pm 1.218^{\mathrm{b}}$ \\
*Citrus peel pectin & $7.23 \pm 0.410$ & $9.08 \pm 0.287$ \\
\hline
\end{tabular}

Values were the means \pm standard deviations of three replicates analysis

*citrus peel pectin was used as a standard for comparison

Ash content is used to determine the purity of pectin. For good quality of pectin, the ash content must be below than 10\% (Girma and Worku, 2016). In this study, the extracted pectin contains $8.73 \%$ of ash content which is not significantly different than the ash content found in commercial pectin $(9.08 \%)$. The present finding seems to be consistent with other research which found the ash content below 10\% (Bhat and Singh, 2014; RamLi et al., 2014). The previous study also suggested that the value of ash in dragon fruit peel pectin can form better gels than that from citrus peel pectin.

\subsection{WHC, OHC and SC of extracted pectin}

Table 2 compares the result of $\mathrm{WHC}, \mathrm{OHC}$ and SC obtained from extracted dragon fruit peel pectin and citrus peel pectin. The results were expressed in mean and standard deviations (S.D). The ability of a material to retain water and oil following the centrifugation is dependent on its WHC and OHC. Specifically, WHC signifies the ability of soluble dietary fiber to absorb and retain water to form a viscous solution. In addition to that, high WHC is commonly associated with greater pectin content Rubio-Senent et al., 2015). In this study, the WHC of dragon fruit peel pectin (4.08) is slight lower than the citrus peel pectin (4.61). This current data also shows lower reading than previous study of WHC of dragon fruit peel (5.5). This means that the ability of dragon fruit peel pectin to form gel is poorer than citrus pectin due to lower pectin content (Izalin et al., 2016). However, the value obtained was sufficient to prevent syneresis and to modify texture of foods (Dona, 2019). WHC in pectin is important to maintain the texture of high-fat foods (Mingyue, 2017), improve the sensory attributes and reduce calories of foods (Bouaziz, Rassaoui, and Besbes, 2014). Another significant functional property of some ingredients used in the prepared food is OHC. Ingredients with a high $\mathrm{OHC}$ 
promote stabilization of high fat food products and emulsion, assisting the dispersion of two immiscible liquids (Rubio-Senent et al., 2015). In this study, OHC of dragon fruit peel (2.18) is higher compared to citrus peel pectin (2.083), signified higher pectin content (Rubio-Senent et al., 2015). The possible explanation for this dissimilarity is due to the difference in their chemical and physical structure and polysaccharides (Chia and Chong, 2015). Pectin with higher OHC is widely used as an emulsion in beverages (Dona, 2019) and in soups, baked goods and as an extender in meat (Izalin et al., 2016).

Table 2. Comparison amount of Water Holding Capacity (WHC), Oil Holding Capacity (OHC) and Swelling Capacity (SC) in two samples

\begin{tabular}{ccc}
\hline Samples & WHC & OHC \\
\hline Dragon fruit peel pectin & $4.08 \pm 0.081$ & $2.18 \pm 0.096$ \\
*Citrus peel pectin & $4.61 \pm 0.997$ & $2.083 \pm 0.046$ \\
\hline
\end{tabular}

Values were the means \pm standard deviations of three replicates analysis

* citrus peel pectin was used as a standard for comparison

In this study, the mean score for SC of dragon fruit peel pectin is slightly lower than that of citrus peel pectin. This result may be explained by the fact that different sources of pectin will have different swelling properties, solution and also gel formation (Sriamornsak, 2011). It is important for pectin to have high SC as it will enhance hydrodynamic volume especially when dissolving in water. In the frozen food industry, pectin is required to maintain the juiciness of cooked fish and meat products and to lessen the drip loss with the help of good SC (Gomez-Guillen et al., 2011). In biological application, pectin has been used as a wound care material for having a good swelling capacity (Gupta et al., 2014).

\subsection{Texture profile analysis of dragon fruit peel pectin}

The texture of gel processed from dragon fruit peel pectin was analyzed in terms of hardness, cohesiveness and gumminess and compared with commercial pectin gel. Figure 4(a) shows the image of gel made up from extracted pectin and figure $4(\mathrm{~b})$ is the gel from citrus peel pectin. Sucrose was added into the pectin solution during gel processing. This is to dehydrate the pectin by competing for water and reduce its ability to stay in a dispersed state. Sugar also reinforce the junction zones between pectin molecules and strengthen the hydrophobic interactions between methyl groups (Niezgoda, 2015). Formation of gel occurred due to the bonding of hydrogen in between of free carboxyl groups on the pectin molecules and the hydroxyl groups of neighboring molecules (Pilgrim et al., 1991). In this study, the value of hardness and gumminess of dragon fruit peel pectin gel is higher than that of commercial pectin gel (Table 3). For cohesiveness, the mean value is similar in both gels and the result is harmony with previous researchers (Izalin et al., 2016). Further statistical analysis revealed that there were no significant difference between two different gels for all attributes. This result is in good agreement with the previous report which stated that the gelling quality of extracted pectin was comparable to that of commercial pectin (Nazaruddin et al., 2011). Therefore, it can be concluded that gel produced from dragon fruit peel has an excellent texture comparable to commercial pectin gel.

(a)

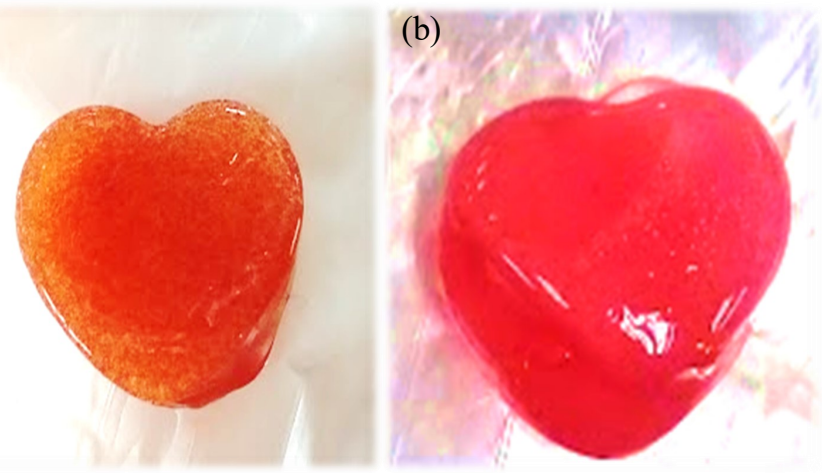

Figure 4. Gels produced from (a) dragon fruit peel pectin and (b) citrus peel pectin

Table 3. Comparison attributes of two different samples

\begin{tabular}{ccc}
\hline Attributes & $\begin{array}{c}\text { Dragon fruit peel } \\
\text { pectin gel }\end{array}$ & $\begin{array}{c}* \text { Citrus peel pectin } \\
\text { gel }\end{array}$ \\
\hline Hardness $(\mathrm{g})$ & $31.63 \pm 3.81$ & $29.77 \pm 1.97$ \\
Cohesiveness $(\mathrm{g} / \mathrm{s})$ & $1.06 \pm 0.08$ & $1.06 \pm 0.05$ \\
Gumminess & $33.66 \pm 6.05$ & $31.55 \pm 2.43$ \\
\hline
\end{tabular}

Values were the means \pm standard deviations of three replicates analysis

*citrus peel pectin was used as a standard for comparison

\section{Conclusion}

Dragon fruit peel is usually discarded after the consumption of the fruit's flesh. The copious of waste that is produced from this operation will contribute to environmental pollution. Since the peel provides many advantages, researchers found a way to turn it from waste to wealth, by extracting pectin from the peel. Dragon fruit peel is one of the potential sources to supply the market demand for pectin. Results obtained indicate that dragon fruit peel pectin is of the high methoxyl pectin type and this is important for further applications in the food industry. Melting properties of extracted pectin show no significant difference when compared with commercial pectin. The extracted sample is pure and original as supported by the ash analysis. However, further analysis should be given attention especially on the moisture content to ensure that the quality of pectin is established. Overall, other physicochemical analysis and 
texture profile analysis concluded that the extracted pectin have good potential to become another source of pectin. The quality of pectin is as good as pectin from citrus peel pectin.

\section{References}

Abang Zaidel, D.N., Md Rashid, J., Hamidon, N.H., Md Salleh, L. and Mohd Kassim, A.S. (2017). Extraction and characterization of pectin from dragon fruit (Hylocereus polyrhizus) peels. Chemical Engineering Transactions, 56, 805-810. https:// doi.org/10.3303/CET1756135

Ahmed, S. and Sikder, B.H. (2019). Extraction, Characterization and Application of Three Varieties of Citrus limon L. pectin in Jelly Product. Food and Applied Bioscience Journal, 7(1), 31-50.

Bhat, S.A. and Singh, E.R. (2014). Extraction and Characterization of Pectin from Guava Fruit Peel. International Journal of Research in Engineering and Advanced Technology, 2(3), 1-7.

Bouaziz, M.A., Rassaoui, R. and Besbes, S. (2014). Chemical Composition, Functional Properties, and Effect of Inulin from Tunisian Agave americana L. Leaves on Textural Qualities of Pectin Gel. Journal of Chemistry, 2014, 758697. https:// doi.org/10.1155/2014/758697

Castillo-Israel, K.A.T., Baguio, S.F., Diasanta, M.D.B., Lizardo, R.C.M., Dizon, E.I. and Mejico, M.I.F. (2015). Extraction and characterization of pectin from Saba banana [Musa 'saba'(Musa acuminata $\mathrm{x}$ Musa balbisiana)] peel wastes: A preliminary study. International Food Research Journal, 22(1), 202207.

Chia, S.L. and Chong, G.H. (2015). Effect of Drum Drying on Physico-chemical Characteristics of Dragon Fruit Peel (Hylocereus polyrhizus). International Journal Food Engineering, 11(2), 285293. https://doi.org/10.1515/ijfe-2014-0198

Coelho, E.M., Azevedo, L.C.D., Viana, A.C., Ramos, I.G., Gomes, R.G., Lima, M.D.S. and Umsza-Guez, M.A. (2017). Physico-chemical properties, rheology and degree of esterification of passion fruit (Passiflora edulis f. flavicarpa) peel flour. Journal of Science Food Agriculture, 98(1), 166-173. https:// doi.org/10.1002/jsfa.8451

Dona, S.M.J. (2019). Isolation and Characterization of Pectin from Pumpkin (Cucurbita maxima) Waste and Its Food Application. Asian Food Science Journal, 13(2), 1-9. https://doi.org/10.9734/ afsj/2019/v13i230104

Girma, E. and Worku, M.T. (2016). Extraction and Characterization of Pectin From Selected Fruit Peel
Waste. International Journal of Scientific and Research Publications, 6(2), 447-454.

Gomez-Guillen, M.C., Gimenez, B., Lopez-Caballero, M.E. and Montero, M.P. (2011). Functional and bioactive properties of collagen and gelatin from alternative sources: A review. Food Hydrocolloids, 25(8), 1813-1827. https://doi.org/10.1016/ j.foodhyd.2011.02.007

Gupta, B., Tummalapalli, M., Deopura, B.L. and Alam, M.S. (2014). Preparation and characterization of insitu crosslinked pectin-gelatin hydrogels. Carbohydrate Polymers, 106(1), 312-318. https:// doi.org/10.1016/j.carbpol.2014.02.019

Hashim, A.Z. (2018). Extraction and Characterization of Pectin from Dragon Fruit (Hylocerens polyrhizus) Peel Using Different Concentration of Ammonium Oxalate. Basrah Journal of Agricultural Sciences, 31 (1), 12-19. https://doi.org/10.21276/basjas

Hoe, K. (2017). Planting Density of Red Pitaya (Hylocerens polyrhizus) to Achieve Optimum Yield Under Malaysia Weather Condition. International Journal of Agriculture Innovations and Research, 6 (2), 354-358.

Ismail, N.S.M., RamLi, N., Hani, N.M. and Meon, Z. (2012). Extraction and characterization of pectin from dragon fruit (Hylocereus polyrhizus) using various extraction conditions. Sains Malaysiana, 41 (1), 41-45. https://doi.org/10.3303/CET1756135

Izalin, M.Z.N., Kharidah, M., Jamilah, B. and Noranizan, M.A. (2016). Functional properties of pectin from dragon fruit (Hylocereus polyrhizus) peel and its sensory attributes. Journal of Tropical Agriculture and Food Science, 44(1), 95-101.

Jaswir, I., Alotaibi, A., Jamal, P., Octavianti, F., Lestari, W., Hendri, R. and Alkahtani, H. (2016). Optimization of extraction process of plant-based gelatin replacer. International Food Research Journal, 23(6), 2519-2524.

Jauhari, N.K., Ibrahim, D., Ibrahim, M., Yahya, M.N.A., Nor, N.M., Isa, K.A.M. and Hazali, N. (2013). Proximate composition and antioxidant activity of dried belimbing dayak (Baccaurea angulata) fruits. Sains Malaysiana, 42(2), 129-134.

Khan, M., Bibi, N. and Zeb, A. (2015). Optimization of Process Conditions for Pectin Extraction from Citrus Peel. Science, Technology and Development, 34(1), 9-15. https://doi.org/10.3923/std.2015.9.15

Mamet, T., Yao, F., Li, K. and Li, C. (2017). Persimmon Tannins Enhance The Gel Properties of High and Low Methoxyl Pectin. LWT - Food Science and Technology, 86, 594-602. https://doi.org/10.1016/ j.lwt.2017.08.050 
Marić, M., Grassino, A.N., Zhu, Z., Barba, F.J., Brnčić, M., and Brnčić, S.R. (2018). An overview of the traditional and innovative approaches for pectin extraction from plant food wastes and by-products: Ultrasound-, microwaves-, and enzyme-assisted extraction. Trends in Food Science and Technology, 76, 28-37. https://doi.org/10.1016/j.tifs.2018.03.022

Mhd Sarbon, N., Badii, F. and Howell, N.K. (2013). Preparation and characterisation of chicken skin gelatin as an alternative to mammalian gelatin. Food Hydrocolloids, 30(1), 143-151. https:// doi.org/10.1016/j.foodhyd.2012.05.009

Mohamadzadeh, J., Sadeghi-Mahoonak, A.R., Yaghbani, M. and Aalami, M. (2010). Extraction of pectin from sunflower head residues of selected iranian cultivars. World Applied Science Journal, 8(1), 21-24.

Mohamed, H. (2016). Extraction and Characterization of Pectin from Grapefruit Peels. MOJ Food Processing and Technology, 2(1), 31-38. https:// doi.org/10.15406/mojfpt.2016.02.00029

Muhammad, K., Mohd. Zahari, M.I., Gannasin, S.P., Adzahan, N.M. and Bakar, J. (2014). High methoxyl pectin from dragon fruit (Hylocereus polyrhizus) peel. Food Hydrocolloids, 42(Part2), 289-297. https://doi.org/10.1016/j.foodhyd.2014.03.021

Nurul, S.R. and Asmah, R. (2014). Variability in nutritional composition and phytochemical properties of red pitaya (Hylocereus polyrhizus) from Malaysia and Australia. International Food Research Journal, 21(4), 1689-1697.

Pilgrim, G.W. Walter, R.H. and Oakenfull, D.G. (1991). The chemistry of high methoxyl pectin. In Walter, R.H. (Ed.). The chemistry and Technology of Pectin. USA: Elsevier.

Rascón-Chu, A., Martínez-López, A.L., Carvajal-Millán, E., Ponce de León-Renova, N.E., MárquezEscalante, J.A. and Romo-Chacón, A. (2009). Pectin from low quality "Golden Delicious" apples: Composition and gelling capability. Food Chemistry, 116(1), 101-103. https://doi.org/10.1016/ j.foodchem.2009.02.016

Rubaiyi, M.Z., Zularisam, A.W. and Mimi Sakinah, A.M. (2016). Effect of Process Parameters on Pectin Extraction from Dragon Fruit (Hylocereus polyrhizus) Peels via Chemical and Physical Treatment. Australian Journal of Basic and Applied Sciences, 10(17), 69-74.

Rubio-Senent, F., Rodriguez-Gutierrez, G., LamaMunoz, A., Fernandez-Bolanos, J. (2015). Pectin extracted from thermally treated olive oil byproducts: Characterization, physico-chemical properties, in vitro bile acid and glucose binding.
Food Hydrocolloids, 43, 311-321. https:// doi.org/10.1016/j.foodhyd.2014.06.001

Sharma, P.C., Gupta, A. and Kaushal, P. (2014). Optimization of method for extraction of pectin from apple pomace. Indian Journal of Natural Products and Resources, 5(2), 184-189.

Sriamornsak, P. (2003). Chemistry of pectin and its pharmaceutical uses: a review. Silpakorn University International Journal, 3(1-2), 207-228. https:// doi.org/10.5458/jag.54.211

Sriamornsak, P. (2011). Application of pectin in oral drug delivery. Expert Opinion on Drug Delivery, 8 (8), 1009-1023. https:// doi.org/10.1517/17425247.2011.584867

Tang, P.Y., Wong, C. and Woo, K. (2011). Optimization pectin extraction dragon fruit (Hylocereus polyrhizus). Asian Journal of Biological Sciences, 4 (2), 189-195. https://doi.org/10.3923/ ajbs.2011.189.195

Tongkham, N., Juntasalay, B., Lasunon, P. and Sengkhamparn, N. (2017). Dragon fruit peel pectin: Microwave-assisted extraction and fuzzy assessment. Agriculture and Natural Resources, 51(4), 262-267. https://doi.org/10.1016/j.anres.2017.04.004

Wang, W., Ma, X., Jiang, P., Hu, L., Zhi, Z., Chen, J., Ding, T, Ye, X. and Liu, D. (2016). Characterization of pectin from grapefruit peel: A comparison of ultrasound-assisted and conventional heating extractions. Food Hydrocolloids, 61, 730-739. https://doi.org/10.1016/j.foodhyd.2016.06.019

Wang, X., Chen, Q. and Lü, X. (2014). Pectin extracted from apple pomace and citrus peel by subcritical water. Food Hydrocolloids, 38, 129-137. https:// doi.org/10.1016/j.foodhyd.2013.12.003

Zaid, R.M., Mishra, P., Tabassum, S., Ab Wahid, Z. and Sakinah, A.M.M. (2019). High methoxyl pectin extracts from Hylocereus polyrhizus peels: Extraction kinetics and thermodynamic studies. International Journal of Biological Macromolecules, 141, 1147-1157. https://doi.org/10.1016/ j.ijbiomac.2019.09.017 